\title{
Are Schools of Education Failing the Tertiary Mathematics Sector?
}

\author{
Heather Mays \\ School of Education, University of New \\ England, Armidale. Australia. \\ hmays@metz.une.edu.au
}

\author{
John Yearwood \\ School of Information Technology \& \\ Mathematical Sciences, University of \\ Ballarat. Australia. \\ j.yearwood@ballarat.edu.au
}

\begin{abstract}
In the 1990s, two major issues emerged globally for tertiary mathematics educators: declining standards in the mathematical proficiency of students at tertiary-entry level and the advocates for the incorporation of IT into the processes of teaching and learning. Addressing these issues required significant reform of both curriculum content and classroom practice to ensure that the technology was used appropriately and effectively. These reforms were largely implemented by staff from tertiary Schools of Mathematics. Rather than leading the reform, the Education community lagged behind and in some instances has taken research into the use of IT in Mathematics Education in a questionable direction. In this paper, we outline what we contend has been a failure on the behalf of the Education community to tackle and address problems experienced by mathematics educators (particularly at the tertiary level) and make some suggestions for the directions of future research in Mathematics Education.
\end{abstract}

\section{Background}

Despite the major algebra reforms that were conducted in the UK and the US in the 1970s and 1980 s, standards in algebra at tertiary entry level have continued to decline [10]. As a result, Schools of Mathematics at many universities have introduced diagnostic tests for students entering science and engineering courses. The results of the tests have been used to adapt curriculum and confront ${ }^{1}$ students with the sources of their errors. Follow-up studies revealed that algebraic deficiencies can be overcome by the use of targeted remediation [7, 21].

The introduction of IT into all facets of life accelerated throughout the 1990s. Mathematics education was no exception. Calculators were already commonplace in mathematics classrooms but the advent of CASs (computer algebra systems) provided lecturers with the opportunity to revolutionise their teaching. Thus, simultaneous with addressing the need to identify and remedy shortcomings in the mathematical understanding of their students, Mathematics lecturers were confronted with the development and implementation of integrated curricula and appropriate assessment techniques [22]. What has emerged is the need for a critical review of research into the use of IT (particularly CASs) in Mathematics classrooms at both secondary and tertiary levels $[23,14]$.

In the next section, we detail how these two issues have been addressed in some Australian universities and examine the roles played by both Mathematics and Education staff.

\section{Diagnostic testing}

Whilst the last twenty years has seen a dramatic increase in the production of computerised teaching/learning systems, there has been a concomitant decrease in the research

\footnotetext{
${ }^{1}$ Whilst in an ideal world, assistance may have focussed on these areas, often pressures and resource constraints permitted little more than this.
} 
interest accorded to cognitive diagnosis [15]. As a result there is a dearth of systems that are capable of adequately explaining the errormaking process $[1,10]$. In the absence of suitable technology, universities have approached diagnostic testing in two main ways - the use of pen-and-paper tests and the development of online testing shells. We now consider the results from two such research projects at Australian universities.

\subsection{Curtin University of Technology}

Curtin University of Technology is a large university in Western Australia with large enrolments in Science and Engineering courses. At Curtin, the Department of Mathematics made the decision to introduce diagnostic testing for entry-level students, and to use information technology wherever appropriate to improve teaching and assessment practices [5]. Due to the size of the student cohort, staff took the decision to develop an on-line testing shell (MQUEST), which contains a bank of hard-coded questions in multiple-choice format [6]. Students are presented with a set of randomly chosen questions. Once these have been marked, the system advises the student about areas of mathematics that (s)he needs to address, as well as the units in which to enrol. The system does not provide diagnosis beyond this level.

\subsection{The University of Melbourne}

In 1989, the School of Mathematics at the University of Melbourne introduced a diagnostic test for all students entering Science and Engineering courses. This occurred despite the fact that the cohort of students at the University of Melbourne is traditionally one of the best, as measured by entrance scores gained at Year 12 [18]. The diagnostic test contained short-answer questions in four sections - algebra, graphing, calculus and trigonometry. Analysis of student workings on the diagnostic test revealed that students exhibited many of the common misconceptions that have been reported in the literature $[9,16,12]$. This led to the adoption of the conflict teaching approach and students showed dramatic improvement $[19,20]$. Followup studies indicated that students had improved their error-checking procedures and self- corrected many of their original mistakes, i.e., the immediate effect of the conflict teaching approach was successful in reducing the incidence of the common misconceptions [21]. These results then raised the question of how persistent the improvement would be. Therefore, a follow-up study was conducted with a subgroup of the original treatment group [19]. The results of the research showed that overall the group showed significant and sustained improvement from their first diagnostic test. Swedosh was careful not to extrapolate the results beyond the group under investigation. However, he concluded that the conflict approach was successful in reducing the incidence of misconceptions with students who were strong mathematically.

This research has been particularly valuable for a number of reasons: it involved large-scale, quantitative research, it identified a problem, developed remedial action leading to improved classroom practice, and it involved evaluation of the solution in terms of immediacy and sustainability. It was conducted completely under the auspices of the School of Mathematics.

In the next section, we consider the use of IT in Mathematics education and examine one project involving the use of CASs.

\section{Computer Algebra Systems}

In the early 1990s in Australia, funding for university teaching projects was provided by CAUT (Committee for the Advancement of University Teaching). Various projects were funded across all disciplines, although the emphasis was upon multidisciplinary projects. One such project was conducted by the School of Information Technology and Mathematical Sciences (SITMS) and the School of Engineering at the University of Ballarat. It focused on problem-based learning and the use of CASs to promote connections between mathematics and engineering units. Several student-centred, problem-based projects that integrated engineering and mathematical studies were developed and the use of CAS was integrated where appropriate into all stages of the projects. The projects all comprised problem analysis, mathematical modelling and simulation, design and reformulation, construction and testing and solution validation.

The CAUT project built upon the reform of the Mathematics curriculum that had already taken place in SITMS and later formed the basis 
for the design of the new Engineering course [11, $22,17]$. The results included both qualitative and quantitative research, and the significance of the project can be measured not only by its success in driving curriculum reform at the University of Ballarat but also because it raised a number of issues about the use of CAS [23]. These are summarised in the next section.

\section{CAS in mathematics education}

At this point, it is important to note that the motivation for designing and building CASs was the need for high-speed, symbolic tools to assist mathematics researchers. Computers (and CASs) are neither mathematicians nor mathematics teachers. Rather, they are tools to aid the practice and learning of mathematics, and it is important that teaching support materials are not reduced to recipes for learning the syntax of a computing package.

A lesson should be learned from the area of Statistics, where access has been enabled by the development of spreadsheets and purpose-built statistical software. However using a statistical package does not a statistician make! Unless care is taken, the teaching of Statistics can quickly degenerate into recipes for button-pushing without any problem analysis. This approach ignores the importance of helping students to develop suitable processes for problem solving. For example, if students apply a hypothesis test to a data set without ever considering the distribution of data, they are in danger of applying an inappropriate test and hence of drawing incorrect inferences. To avoid repeating the mistakes made in Statistics education, we stress the need for students to understand the concepts and to have mastered the associated skills before the student is introduced to sophisticated tools such as CASs. This requires all mathematics units to be taught by specialists. Equally, it is important that staff and students alike do not assume that a CAS obviates the need for mathematics in Science and Engineering courses, nor that a CAS will of itself make up for gaps in a student $s$ understanding of mathematical concepts.

The findings from the CAUT project regarding the most appropriate use of CASs in the mathematics classroom can be summarised as:

- At early stages, students need to develop pattern recognition and abstraction in problem solving. This is aided by teaching in an object-oriented manner where emphasis is placed on the relationship between objects and methods [8].

- Paper-based methods, such as text editing, are more appropriate than CASs for determining a student s ability to process relevance of information.

- CASs are not good at early pedagogy. They are tools designed for use by mathematicians, NOT as aids to learning basic skills. They are appropriately used only when the student has mastered the required skills and understands the underlying concepts.

- CASs are good at the conjecture stage for quick feedback, but if students cannot conjecture, then support materials for CAS can degenerate into nothing more than recipes for button-pushing. Thus students need to learn and practise skills such as conjecturing.

- CASs are efficient at allowing alternative formulations of problems. Seeking agreement of solutions amongst the different formulations is a sound learning approach but this is not appropriate for students struggling with a single approach to a problem.

In conclusion we found that the place for CASs in the mathematics classroom is limited. They are particularly useful for project-based work to enable visualisation and for conducting sensitivity analysis of the inputs and parameters of functions, but are not intended to replace mathematical knowledge.

\section{Directions for Future Research}

We now consider how the issues of cognitive diagnosis and the use of IT have been addressed by the Education community in Australia and make some suggestions for future directions in educational research.

\subsection{Cognitive Diagnosis}

Cognitive diagnosis has largely been ignored since the late 1980 s because it was recognised as being very difficult to effect. Later attempts at student modelling for interactive learning environments (ILEs) therefore tended to shift the emphasis from cognitive diagnosis to other attributes including affective factors (e.g. motivation and self-concept), and conative factors (e.g. the student s wants, intentions and learning style). This shift in emphasis was driven by several observations: ILEs can perform satisfactorily without involving cognitive 
diagnosis, human teachers do not overtly spend much time in diagnosis, it is very difficult, if not impossible, to maintain a complete and accurate model of the student and cognitive diagnosis is only used to direct remediation [15].

Self addressed these observations and stressed the need to revisit the area of cognitive diagnosis and to develop rigorous methods for achieving it. In particular, he noted that cognitive diagnosis need not be restricted to remedial purposes only. The fact that classroom teachers do not overtly spend much time in diagnosis does not mean that they do not undertake such activities. Even if it were the case that human teachers never undertake diagnosis, computerised systems should not be restricted to emulating human performance, instead they should complement it. Whilst cognitive diagnosis is difficult to achieve, it is still important to identify student difficulties, particularly those that are recurrent, because they represent genuine misconceptions on the student s behalf.

It is time to revisit cognitive diagnosis in the area of mathematics. Algebra research led to the development of libraries of mal-rules that were used as the basis of design for early algebra diagnostic systems [16], which were evaluated in situ and which were incorporated into teacher preparation courses. Little progress has been made since then with the notable exception of DIAGNOSYS [1, 2, 3]. The proliferation of artificial intelligence paradigms now available provides opportunities for developing systems with much greater diagnostic capability [10]. Educationists need to be involved in this research because it has implications for the preparation of teachers at all levels.

\subsection{The appropriate use of CAS}

The use of CAS is an issue that is particularly disturbing to the authors. The lessons learned by the tertiary Mathematics sector do not seem to be advising practice or research in Schools of Education. Instead of large-scale, quantitative research projects, within Education there has been a proliferation of poorly directed, smallscale research projects that have not contributed to understanding or to theoretical development that might provide clearer insights into the issues discussed here. As a result, the research has had little impact on improving learning or on changing classroom practice. Indeed, much of the current research in this area represents no new knowledge, but is simply a change in the mode of delivery of materials developed as part of earlier reforms. This has negatively impacted on the reputation of the Education community and brought attention to the lack of progress in areas that are of great concern globally.

This was possibly best summarised in the closing address to ICMI01 [4]. Concerns that were raised included:

- The conference ignored the issue of providing evidence on how technology can support the learning and doing of different aspects of algebra. The focus tended to be on teaching materials, rather than the theory that led to their development. In other words, the research was not new knowledge but just a different treatment of materials that had been developed as part of earlier algebra reforms.

- The power of algebra as a tool for solving problems outside the domain of mathematics received little attention.

- There is a need for different types of educational research beyond small-scale, anecdotal projects that fail on three standard indicators of research quality - generalizability, trustworthiness and importance. The authors would add sustainability to this list.

The reason for the authors concerns is that CASs are now infiltrating the secondary system, with extravagant claims being made as to their role and capability with only a handful of case studies as evidence. This begs the question: What is the purpose of Mathematics Education research? If it is to prepare teachers who adopt the best possible classroom practices, it must move beyond its current state (which, at some institutions, is largely a combination of actionbased research projects and limited empirical studies). In particular, the focus should shift to large-scale projects that are conducted in situ and that include, when appropriate, both tertiary mathematics educators and mathematicians [14]. The way to move on is to build layered curricula that support student development in mathematics, reasoning, analytic ability and clear thinking based on better teaching practice and the appropriate use of IT. This also necessitates reforms in teacher preparation programs.

\section{Conclusion}

Global political factors mean that we can expect that the future for Mathematics Education will be one of poverty! We must therefore use our resources wisely. A basic premise of all good 
design analysis (from multiple regression to dress design) is that if an element does not contribute significantly to the whole, then that element should be removed. In the present context, this leads to a number of questions Just how much IT do we need?, Who uses it?, When is it used?, Is there really evidence to support the claims that are being made with regard to its capabilities? . In short, it is time for a critical review of the use of IT in Mathematics Education using standard indicators of success [13]. Areas that need to be addressed include cognitive diagnosis, developing teaching techniques to overcome student difficulties, research into the sustainability of observed improvements, preparing teachers appropriately in terms of their own mathematical knowledge and their ability to assess student competence. The most important question to be addressed is What is the appropriate use of IT in the teaching and learning of Mathematics? .

\section{References}

[1] J. Appleby, DIAGNOSYS - User s Guide v. 3.3 Department of Engineering Mathematics, University of Newcastle upon Tyne. 2000

[2] J.Appleby, and A. Anderson, Diagnostic testing in mathematics and mechanics on entry Proc. IMA Conf. Math. Education of Engineers, Loughborough, UK. 1997.

[3] J. Appleby, P. Samuels and T. Treasure-Jones, DIAGNOSYS - A Knowledge-Based Diagnostic Test of Basic Mathematical Skills Computers in Education Vol. 28, No. 2, 1997. pp. 113-131

[4] H. Burkhardt, Where Next? Some comments on implementation Closing Address, ICMI Algebra Conf. University of Melbourne. December, 2001.

[5] L. Caccetta, P. Hollis, P. Siew, and B. White, Increased support for the teaching and learning of first-year mathematics Mathematics - creating the future Proc. 16 th AAMT Conf. 1997. pp. 57-60

[6] L. Caccetta, P. Hollis, P. Siew, and B. White, Computer based diagnostic testing Mathematics creating the future Proc. 16 th AAMT Conf. 1997. pp. 66-70

[7] P. Edwards, How effective is the Mathematics Diagnostic Test and Follow-up Support Combination? Teaching Mathematics and Its Applications Vol. 16, No. 3, 1997. pp. 23-27

[8] L.D. English, Mathematical Reasoning: Analogies, Metaphors and Images Lawrence Erlbaum Associates Mahwah, NJ. 1997.

[9] M. Matz, Towards a Computational Theory of Algebraic Competence J. Mathematical Behaviour, Vol. 3, No. 1-2, 1980. pp. 93-166

[10] H. Mays, A Cognitive Diagnostic System for Explaining Algebra Errors Ph. D. thesis, SITMS, University of Ballarat. 2002.
[11] H. Mays, J. Yearwood, and B. Glover, A Report on Curriculum Development involving Computer Algebra Systems in Mathematics: 1990-1995 in Proc. AEMC96. Sydney, July, 1996. pp. 581-586.

[12] S. Payne, and H. Squibb, Algebra Mal-Rules and Cognitive Accounts of Error Cognitive Science, Vol. 14. 1990. pp. 445-481

[13] Y. Reich, Measuring the Value of Knowledge Int l. J. Human-Computer Studies, Vol. 42, No. 1, 1995. pp. 3-30.

[14] A. Rubinov, B. Glover, and H. Mays, Mathematics and Computation - What should our Schools be teaching? Vinculum, Vol. 35, No. 4. 1998. pp. 13-22.

[15] J. Self, Deconstructionist Student Models in the Computer-Based Learning of Science in Sanchez, A. D. and de Castro, I. F. (Eds.) Proc. 3 rd Int 1 Conf., CALISCE96, San Sebastian, Spain. July, 1996. pp. 27-37

[16] D. Sleeman, An Attempt to Understand Students Understanding of Basic Algebra Cognitive Science Vol. 8, 1984. pp. 387-412

[17] A. Subic, J. Yearwood, B. Glover, and H. Mays, Problem-centred Learning Using Computer Algebra Systems in the Engineering Curriculum European J. Eng. Education, Vol. 21, No. 1, 1996. pp. 41-54

[18] P. Swedosh, Mathematical Misconceptions Commonly Exhibited by Entering Tertiary Mathematics Students in Clarkson, P. (ed.) Technology in Mathematics Education Melbourne: MERGA. 1996. pp. 534-541.

[19] P. Swedosh, Reducing the Incidence of Mathematical Misconceptions in 'Middle Band' Students . In Truran, J. and Truran, K. (Eds.) Making the Difference Adelaide: MERGA. 1999. pp. 469-476.

[20] P. Swedosh, and J. Clark, Mathematical Misconceptions Can We Eliminate Them? in Biddulph, F. and Carr, K. (Eds.) People in Mathematics Education, Waikato: MERGA, 1997. pp. 492-499

[21] P. Swedosh, and J. Clark, Mathematical Misconceptions - We have an Effective Method for Reducing Their Incidence But Will the Improvement Persist? In C. Kanes et al (Eds.), Teaching Mathematics in New Times (2), Broadbeach: MERGA. 1998. pp. 588-595.

[22] J. Yearwood, and B. Glover, Computer Algebra Systems in Tertiary Engineering Mathematics Australasian J. Eng. Education Vol. 6, No. 1, 1995. pp. 87-94

[23] J. Yearwood, B. Glover, and H. Mays, Technology and Mathematics Education: A Critical Need for Objective Curriculum Reform Science, Mathematics \& Technology Education and National Development Proc. Int 1 Conf. Science, Mathematics and Technology Education, Hanoi Pedagogy University, Vietnam. 1997. pp. 270-275. 